\title{
FERRAJOLI, O EL NEOCONSTITUCIONALISMO NO TOMADO EN SERIO
}

\author{
Mauro Barberis \\ Traducción de Diego Dei Vecchi
}

RESUMEN. Esta última contribucción de Ferrajoli al debate sobre el (neo)constitucionalismo requiere cinco críticas: primero, el enfoque deductivista coherentemente adoptado por el autor desde Teoría assiomatizzata del diritto hasta Principia iuris deja muy poco espacio para la interpretación y la argumentación en el razonamiento jurídico; segundo, el propio problema de la relación entre derecho y moral no está verdaderamente discutido por él; tercero, cuarto y quinto, el mismo enfoque deductivista fuerza a Ferrajoli a reducir los principios a reglas, a ignorar el papel democrático que podría cumplir una ponderación actuada por el legislador y no por el juez, y a resolver de una discutible manera monista el problema pluralista del conflicto entre derechos.

Palabras clave: (neo)constitucionalismo, relación derecho-moral, principios, ponderación, pluralismo de los valores.

ABSTRACT. This Ferrajoli's last contribution to debate on (neo)constitutionalism deserves five criticism: first, deductivist approach coherently adopted by the author from Teoria assiomatizzata del diritto to Principia iuris leaves too little a stance for interpretation and argumentation in legal reasoning; second, the very problem of law-morals relations is not discussed but eluded by him, fourth and fifth, the same deductivist approach must constrain Ferrajoli to reduce principles to rules, to ignore the democratic role that could be carried out by a legislative and no-judicial balancing, and to provide a dubious monist answer to the pluralist question of conflict among rights.

Keywords: (neo)constitutionalism, law-and-morals problem, principles, balancing, value pluralism. 


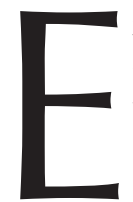

n Constitucionalismo principialista y constitucionalismo garantista (de ahora en adelante CP), mi maestro y amigo Luigi FERRAJOLI despliega la siguiente estrategia teórica. Su teoría del Derecho, como se sabe, fue varias veces apresuradamente asimilada al neoconstitucionalismo: también por parte del suscripto, en el manual Giuristi e filosofi. Una storia della filosofia del diritto (Mulino, Bologna, 2011, pp. 232-234). En CP, reaccionando ante estas asimilaciones, FERRAJOLI toma distancia del neoconstitucionalismo: por él rebautizado, ahora, como constitucionalismo principialista e jusnaturalista y distinguido de su propio constitucionalismo garantista y positivista. Mi trayecto teórico es el opuesto; después de haber elaborado, con Susanna Pozzolo y Paolo COMANDUCCI, la propia noción de neoconstitucionalismo - a fin de criticar las teorías neoconstitucionalistas- hoy estoy convencido de que no es posible liquidar ni la noción ni las teorías. Hoy, en consecuencia, formulo cinco sumarias objeciones al último FERRAJOLI; cuando el lector de Doxa las vea, habrá salido mi Manuale di filosofía del diritto (Giappichelli, Torino, 2011) y también el ensayo Esiste il neocostituzionalismo? (en Analisi e diritto, 2011, pp. 11-30), y espero que entonces mis razones queden más claras.

1. La primera objeción al FERRAJOLI de CP, más general, está dirigida a la misma estrategia teórica adoptada. FERRAJOLI tiene razón al rechazar la asimilación al neoconstitucionalismo de la teoría del Derecho elaborada por él desde Teoria assiomatizzata del diritto (1971) a Principia iuris. Teoria del diritto e della democrazia (Laterza, Roma-Bari, 2007-2009): obra cuya elaboración es anterior al giro neoconstitucionalista, y que, al menos en el primer volumen, continúa la tradición de los grandes sistemas iusracionalistas, de HOBBES a BENTHAM, reformulándola en los términos de la teoría formal iuspositivista. Más aún, FERRAJOLI, tiene razón al criticar al neoconstitucionalismo: posición teórica que en la teoría del Derecho de lengua inglesa une su propia fortuna a la de Ronald DwORKIN, y que en la teoría del Derecho continental, en particular «latina», tal vez está gozando de un éxito superior a sus méritos. Pero CP, desechando la teoría en su totalidad, no sólo evita sus debilidades sino que ignora sus aciertos, con lo que corre el riesgo de desconocer los genuinos problemas por ella planteados.

Las próximas objeciones estarán dedicadas a criticar las soluciones ofrecidas en CP para los tres principales problemas neoconstitucionalistas: conexión Derecho-moral, distinción reglas/principios, ponderación. Aquí querría sólo referirme a las razones teóricas por las que FERRAJOLI no puede proceder de modo diverso, si quiere ser coherente con la base conceptual del primer volumen de Principia iuris. En efecto, bajo este título un tanto engañoso - no obstante la definición estipulativa de «principio» expresamente formulada en la introducción - FERRAJOLI proporciona una teoría de las reglas, no de los principios del Derecho. Para él, como para mí, las reglas se distinguen de los principios por el hecho de ser aplicables deductivamente; para él, como para mí, el sistema deductivo jurídico no puede estar conformado, por definición, más que por reglas, de otro modo no sería un sistema deductivo: y en consecuencia es comprensible, aunque no justificable, que CP intente desembarazarse del problema que los principios plantean para una teoría del Derecho. Pero en el Derecho hay también principios: y ésta, creo yo, es una de la razones por la cuales el Derecho no puede ser reducido al modelo del sistema. Más adelante sostendré que los principios, y el neoconstitucionalismo en general, han de ser tomados más en serio de cuanto lo hace FERRAJOLI. 
2. La segunda objeción, un poco menos general que la precedente, está dirigida al modo en el cual CP se libra del problema de la conexión entre Derecho y moral. También CP renueva la constante adhesión de FERRAJOLI a la tesis de la separación entre Derecho y moral y al iuspositivismo: en particular, a un iuspositivismo hoy llamado por él constitucionalismo garantista. Simétricamente, FERRAJOLI renueva el rechazo de la Tesis de la conexión iusnaturalista y del iusnaturalismo: equiparado a la teoría del Derecho, hoy quizás mayoritaria, por él llamada constitucionalismo principialista y por mí y por otros, más precisamente, neoconstitucionalismo. No es éste el momento de discutir sobre estas etiquetas; naturalmente, no estoy de acuerdo con el rechazo del término «neoconstitucionalismo», rechazo compartido por FERRAJOLI, Manolo ATIENZA y casi toda la teoría del Derecho española: término que sigue pareciéndome mucho menos equívoco que «constitucionalismo». El único problema al que quisiera referirme aquí es al de la conexión Derecho-moral: conexión diversamente teorizada por los diferentes autores neoconstitucionalistas, pero de la cual CP se libera acumulativamente como sigue.

FERRAJOLI comienza banalizando la tesis; obviamente hay conexión entre Derecho y moral, el Derecho siempre ha incorporado normas morales: las constituciones «expresan e incorporan valores ni más ni menos que cuanto lo hacen las leyes ordinarias». Como observa Giorgio PINO, sin embargo, aquí FERRAJOLI no sólo deja de lado el detalle de que las constituciones incorporan expresamente valores morales, sino que además parece usar el viejo argumento kelseniano del Rey Midas: todo aquello que el Derecho toca se convierte en Derecho. Según CP, por tanto, una de dos opciones: o las constituciones incorporan valores sólo en el sentido banal en que lo hacen también las leyes ordinarias; o la constitución misma se transforma en una tabla de valores, y así, de la sartén del legalismo ético iuspositivista se cae en la lumbre del constitucionalismo ético: la idea, descabellada - y expresamente rechazada por parte de todos los autores neoconstitucionalistas - de que las constituciones son justas por definición.

Sobre el punto hay mucha literatura que FERRAJOLI ignora, en el sentido del ingles to ignore, en tanto extraña a sus intereses: por ejemplo, todo el debate entre iuspositivismo inclusivo, exclusivo y normativo. No puedo por cierto criticarlo porque no se apasione por los problemas que sí me apasionan a mí: pero creo que el neoconstitucionalismo plantea al menos tres problemas reales. 1) ¿La positivización de la moral es una cuestión all or notbing, como suponen FERRAJOLI y todos los iuspositivistas, o bien puede haber partes del Derecho, como el Derecho constitucional, menos positivizadas que otras? 2) Las conexiones entre Derecho y moral, aun cuando fueran meramente contingentes, ¿no serían lo suficientemente importantes como para requerir una teoría del Derecho — sea neoconstitucionalista sea iuspositivista- que se ocupe de ellas? 3) ¿Entre conexión sin restricción, típica del Derecho natural tradicional, y no conexión, típica de los iuspositivismos exclusivo y normativo, hay lugar para una tercera postura? Como me hace notar ATIENZA, los (neo)constitucionalistas admiten que si la conexión fuese sin restricción, el Derecho colapsaría en una moral (positiva) particularmente repugnante, en tanto que creada por los jueces caso por caso.

3. La tercera objeción es triple: en primer lugar, FERRAJOLI se libera de la distinción reglas/principios; segundo, lo hace por razones principalmente ideológicas; por último, aunque el suyo sea un intento genuino de defender la democracia parlamentaria, en realidad termina por dejar a ésta sin ninguna función. En primer lugar, después 
de haber constatado que las distinciones corrientes entre reglas y principios son débiles y no fuertes — salvo quizás por lo que se refiere a los principios programáticosFERRAJOLI se libera sin más de toda distinción reglas/principios: «la diferencia entre la mayor parte de los principios y las reglas es por tanto, según creo, no estructural sino poco más que de estilo». Naturalmente FERRAJOLI sabe perfectamente que para arrojar al mar cuarenta años de discusiones sobre el punto son necesarios argumentos teóricos; bien, su más importante argumento teórico, compartido por él con Cristina REDONDO, parece ser el siguiente: los autores neoconstitucionalistas, aunque parten de la exigencia de exaltar la normatividad de los principios constitucionales, terminan involuntariamente por desconocerla.

En los términos mismos de CP: la distinción reglas/principios produciría «un desconocicmiento de la normatividad de los principios constitucionales», «cuyo respeto [sería] dejado a la discrecionalidad argumentativa del intérprete», renunciando así a esa normatividad fuerte de la constitución que FERRAJOLI glorifica al final. Dicho de otro modo, si se admitiese en teoría que las disposiciones constitucionales expresan (no reglas, sino) principios, aplicables (no por deducción sino) por ponderación, se volvería en la práctica a la negación del carácter prescriptivo de la constitución que era común en el Estado legislativo. La pregunta aquí es la siguiente: ¿deberíamos negar una distinción conceptual entre reglas y principios, tan débil como se quiera, sólo porque admitirla supondría hacer normativamente más débiles nuestras constituciones rígidas, y en particular la italiana? Personalmente, estoy dispuesto a salir a la calle para defender mi constitución: pero cuando hago teoría del Derecho, avalorativamente, esto me permite reconocer que hay una distinción entre reglas y principios.

Normalmente, quien escribe practica el principio de caridad interpretativa y detesta ir a la caza de ideologías; pero aquí la ideología está por todas partes, porque tanto FERRAJOLI como los autores neoconstitucionalistas quieren exaltar la normatividad de la constitución, aunque lo hagan por medios diversos: el primero interpretando la constitución exclusivamente como un conjunto de reglas, los segundos como un conjunto de principios. Buscando una adaptación entre las dos posiciones, se podría decir que la constitución consta, dependiendo ello de la interpretación que se haga, de reglas o de principios; muchas disposiciones constitucionales en materia penal o de libertad individual son en efecto, y quizás deberían ser interpretadas como auténticas reglas; muchas disposiciones en materia civil o de derechos sociales son interpretadas, y quizás deberían serlo, como principios. Esta solución es, por otra parte, menos salomónica de cuanto podría parecer: bien vista presupone una distinción, aunque débil, entre reglas y principios, y en consecuencia da la razón a los neoconstitucionalistas.

Creo que sobre este punto los neoconstitucionalistas tienen razón también por otro motivo, quizás todavía más importante: motivo que tal vez no se subraya suficientemente. La distinción reglas/principios permite explicar el rol democrático del Parlamento en la realización de los principios constitucionales: y explicarla mucho mejor que FERRAJOLI quien, sin embargo, también quisiera exaltar la centralidad del Parlamento en contra del activismo judicial. Si la constitución estuviese compuesta sólo por reglas — como FERRAJOLI está obligado a sostener a partir del sistema deductivo elaborado en Pi1—, entonces al Parlamento no le quedaría función alguna, salvo quizás la de desarrollar los principios programáticos: para deducir, de hecho, no hay necesidad del Parlamento, basta con un 
hombre cualquiera, siempre que esté dotado de razón. Yo creo que el rol asignado al Parlamento en una democracia constitucional es otro; el Parlamento aplica, especifica y pondera - de modos tan diversos como lo son sus cambiantes mayorías- principios constitucionales plurales, genéricos y en conflicto: principios que formulan jurídicamente los valores teorizados por el pluralismo de los valores (value pluralism: cfr. aquí, $\mathbb{\$} 5$ ).

4. Cuarta objeción: la teoría de FERRAJOLI se libera, por las mismas razones, de la ponderación de los principios. La principal inadvertencia neoconstitucionalista —omitir que de la ponderación de principios se obtienen reglas abstractas, y que éstas son aplicables deductivamente- - se le escapa; se percata sólo de que, obviamente, «detrás de cada regla hay un principio». Toda la discusión sobre la ponderación, para él, sería sólo «una burbuja terminológica, inflada enormemente hasta designar las formas más desenvueltas de vaciamiento y de desaplicación de las normas constitucionales». Y aquí vamos de nuevo: CP parece ignorar, siempre en el sentido del inglés «to ignore», que la ponderación es el modo más común de razonar en ética. Esto lo hace notar, en cambio, REDONDO: que sin embargo está de acuerdo con FERRAJOLI respecto a la normatividad de la constitución. Luigi y Cristina, con quienes he discutido ardorosamente sobre este punto, parecen estar aterrados por la pérdida de normatividad de la constitución que se produciría si se admitiera la distinción reglas/principios; yo creo que el de la normatividad es un problema real, sobre todo en las democracias constitucionales menos consolidadas como las latinoamericanas y la italiana: pero creo también que sus preocupaciones son normativas y políticas, no cognoscitivas y teóricas. Desde el punto de vista cognoscitivo, no veo alternativa a reconocer, como se hace en la teoría de las normas al menos desde Georg Henrik vON Wright y el BobBio de Comandi e consigli (1966) hasta AtIENZA y Ruiz MANERO, que sí hay diversos tipos de normas, con diferentes papeles y fuerzas normativas.

5. Quinta y última objeción: la teoría de FERRAJOLI encarna el punto de vista que es el contradictorio exacto al del pluralismo de los valores: la metaética desarrollada por Max Weber, Isaiah Berlin, Bernard Williams, Joseph Raz y otros. En CP, FeRRAJOLI defiende la misma posición monista defendida por él en estos años sobre los derechos: hay sí conflictos entre valores, principios y derechos fundamentales, pero un conflicto mínimo y marginal, que sería radicalmente reducido si todos aceptasen el sistema de conceptos adoptado en Principia iuris. Aquí, FERRAJOLI apunta sobre todo a los jueces brasileños, quienes habrían inventado derechos ficticios para frustrar la actuación de derechos auténticos: como si todos los jueces pudiesen aplicar su sistema deductivo; como si se pudiese siempre distinguir, sobre esta base, entre derechos auténticos y derechos ficticios; y como si la invención de derechos fuese una exclusividad de los jueces brasileños. Comparto con FERRAJOLI, entre muchas otras, también la convicción de que la ponderación de los derechos, en democracia, debe ser por vía legislativa, no judicial; sin embargo, la admisión de cualquier conflicto y de cualquier clase de ponderación amenaza con minar los pilares de su constitucionalismo garantista: iusracionalismo, deductivismo, monismo ético... ¿Puedo decirlo con un slogan? Si debo elegir, mejor el neoconstitucionalismo que el iuspositivismo de CP. 